\title{
BATNAs in Negotiation: Common Errors and Three Kinds of "No"
}

\section{Citation}

Sebenius, James K. "BATNAs in Negotiation: Common Errors and Three Kinds of 'No'."

Negotiation Journal 33, no. 2 (April 2017): 89-99. (Was Harvard Business School Working Paper, No. 17-055, December 2016.)

\section{Published Version}

http://onlinelibrary.wiley.com/doi/10.1111/nejo.12176/abstract

\section{Permanent link}

http://nrs.harvard.edu/urn-3:HUL.InstRepos:30011594

\section{Terms of Use}

This article was downloaded from Harvard University's DASH repository, and is made available under the terms and conditions applicable to Open Access Policy Articles, as set forth at http:// nrs.harvard.edu/urn-3:HUL.InstRepos:dash.current.terms-of-use\#OAP

\section{Share Your Story}

The Harvard community has made this article openly available.

Please share how this access benefits you. Submit a story.

Accessibility 


$$
\text { H A R VAR D B US INESS SCHOOL }
$$

\section{BATNAs in Negotiation: Common Errors and Three Kinds of "No"}

Jim Sebenius

Working Paper 17-055 


\title{
BATNAs in Negotiation: Common Errors and Three Kinds of "No"
}

\author{
Jim Sebenius
}

Harvard Business School

Working Paper 17-055 


\title{
BATNAs in Negotiation: Common Errors and Three Kinds of "No" v.4.0
}

James K. Sebenius, ${ }^{1}$ December 12, 2016; rev. January 28, 2017

(forthcoming, Negotiation Journal, April 2017)

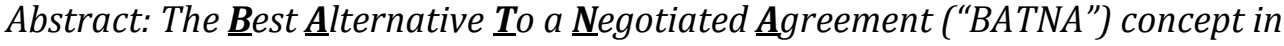
negotiation has proved to be immensely useful. It is widely accepted that a more attractive BATNA ("walkaway option") often increases one's bargaining power. A minimally necessary condition for an agreement to be mutually acceptable is that each side prefers the deal to its BATNA. Thus, the attractiveness of each party's BATNA determines whether a zone of possible agreement - the range within which any mutually acceptable deal must fall-even exists and, if it does, where such a zone is located. ${ }^{2}$ (If either party prefers its BATNA to any proposed deal, then no zone of possible agreement exists.) In tandem with its value in practice, BATNA has become a wildly successful acronym (with over 17 million Google results). Yet the initial characterization of this concept in Getting to Yes (Fisher, Ury, and Patton 1991) along with many later interpretations can be problematic, limiting, and even misleading in a number of ways that this article analyzes and illustrates. First, early characterizations could be easily read to imply that one's BATNA could not itself be a negotiated agreement. Second, and more seriously, common descriptions of one's BATNA as the "best outside option, independent of the other side" needlessly limit its applicability, especially in the many bargaining relationships where BATNAs are inherently interdependent. Third, BATNAs are often mistakenly described mainly as "last resorts" relevant only in case of impasse or "if the other side is more powerful." Other uses of the term "BATNA" such as the common question "How do I negotiate if I have no BATNA?" reflect misconceptions. While savvy negotiators and analysts generally avoid these pitfalls, the less sophisticated can go astray. Robust correctives to these misimpressions are offered and related to three different kinds of "no" in negotiation: a "tactical no," a "no to re-set" that permits away-from-the-table moves to favorably alter the underlying setup, and a "final no."
\end{abstract}

Keywords: negotiation, BATNA, bargaining, zone of possible agreement, reservation price

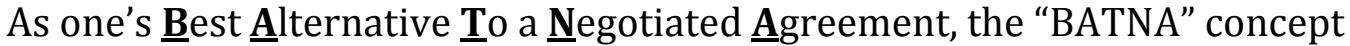
in negotiation has proved to be an immensely useful tool. It is widely accepted that a more attractive BATNA generally increases one's bargaining power. ${ }^{3}$ A minimally necessary condition for an agreement to be mutually acceptable is that each side prefers the deal to its BATNA. Thus, the attractiveness of each party's BATNA determines whether a zone of possible agreement-the range within which any mutually acceptable deal must fall-even exists and, if it does, where such a zone is located. ${ }^{4}$ (If either party prefers its BATNA to any proposed deal, then no zone of possible agreement exists.) In tandem with its value in practice, BATNA has become a wildly successful acronym. Googling it produces over 17 million results, compared to less than 400,000 for its bestselling source, Getting to Yes by Roger Fisher, William Ury, and Bruce Patton (1991).

Yet the initial articulation of the BATNA notion along with many later interpretations can be problematic, limiting, and even misleading. While savvy 
negotiators and analysts generally avoid these pitfalls, the less sophisticated can go astray in at least three ways that I analyze below. (Plus, conceptual precision at the core of one's field is generally a good thing.)

The basic concept underlying BATNAs in negotiation has a long intellectual history, including in game theory as "threat" or "disagreement" points, as David Lax and I (1985) have elsewhere traced. In essence, the Best $\underline{\text { Alternative }}$ To a $\underline{\text { Negotiated }}$ Agreement provides a minimum criterion for evaluating a possible deal: "as compared to what?" This can mean walking away, making something instead of negotiating to buy it, selling to a different customer than your current counterpart, going to court, forging an alternative alliance, taking a strike, and so on. (Far more sophisticated BATNA-related analyses and prescriptions have been developed-for multiparty and coalitional negotiations, for situations with uncertain and dynamic aspects, etc.-but they are beyond the scope of this brief article, which focuses on getting BATNA basics right. ${ }^{5}$ )

Whether or not they explicitly refer to BATNAs skilled practitioners routinely stress the importance to negotiators of persuading the other side that you are able and willing to walk away (ideally to something appealing). For example, Robert Rubin, former U.S. Treasury Secretary and Goldman Sachs co-chair, said "When others sense your willingness to walk away, your hand is strengthened ... Sometimes you are better off not getting to yes." (Rubin and Weisberg 2003: 118, 168). Web TV founder and serial entrepreneur Steve Perlman articulated the common view, bluntly asserting (in my view, too strongly): "If you can't walk away, you can't negotiate." (Sebenius and Fortgang 1999) Hand in hand with this observation is the importance of developing your BATNA before negotiating. As a senior AOL official asserted "You would never do a deal without talking to anyone else. Never.” (Rivlin 2000)

In the course of transforming pharmaceutical startup, Millennium Pharmaceuticals, into a multibillion dollar enterprise, then Chief Business Officer Steve Holtzman explained several rationales for enhancing Millennium's BATNA by adding parties very early in the process: "Whenever we feel there's a possibility of a deal with someone, we immediately call six other people. It drives you nuts, trying to juggle them all, but it will change the perception on the other side of the table, number one. Number two, it will change your self-perception. If you believe that there are other people who are interested, your bluff is no longer a bluff, it's real. It will come across with a whole other level of conviction." (Watkins 1999)

The BATNA acronym has proved catchy with both academics and practitioners. It originated in Getting to Yes with the following explanation: "The reason you negotiate is to produce something better than the results you can obtain without negotiating. What are these results? What is that alternative? What is your BATNA-your Best $\underline{\text { Alternative }} \mathbf{T}$ o a $\underline{\text { Negotiated }}$ Agreement? That is the standard against which any proposed agreement should be measured." (Fisher, Ury, and 
Patton 1991:104). Yet, as appealing and sensible as this concept can be, problems of interpretation and applicability often arise.

Nitpicky semantic problem \#1: Implying That One's BATNA Cannot Be a Negotiated Agreement. Pause, and look back for a moment at the above characterization: the Best Alternative $\mathbf{T O}$ a Negotiated Agreement, "the results you can obtain without negotiating." Or a bit later, helpful advice from Fisher, Ury, and Patton: "Develop your BATNA. Vigorous exploration of what you will do if you do not reach agreement can greatly strengthen your hand." But again, "if you do not reach agreement." (Fisher, Ury, and Patton 1991:103) In other words, your BATNA, as literally characterized, is something other than a negotiated agreement (just walking away?).

As is widely understood-but not from the defining words in Getting to Yesyour BATNA will often be another negotiated agreement; your best alternative to a negotiated agreement with party A may be a better agreement with party B. This need not be the "results you can obtain without negotiating" or the best alternative "TO a negotiated agreement" as the original characterization suggests. Implicitly and obviously, to sort out this minor bit of semantics, one's BATNA must be properly understood as the best alternative "with respect to the negotiation at hand" and not with respect to any negotiated agreement elsewhere.

More serious problem \#2: Characterizing Your BATNA as Your Best Outside Option, Independent of the Other Side. Most BATNA formulations direct your attention to what you can achieve outside the current negotiation and independent of your counterpart. Here's William Ury in Getting Past No (1991: 2122): "Your BATNA is your walkaway alternative. It's your best course of action for satisfying your interests without the other's agreement. [emphasis original]." Harvard Law and Business School Professor Guhan Subramanian (Program on Negotiation 2012:3) frames the BATNA concept with a question: "if your current negotiation reaches an impasse, what's your best outside option? [emphasis added]" More popularly, from Beyond Intractability (Spangler 2012) and countless similar sources: your BATNA "is the best you can do if the other person refuses to negotiate with you--if they tell you to 'go jump in a lake!' or "Get lost!' . . It is the best you can do WITHOUT THEM. [emphasis original]”

While often useful, this common and unambiguous focus on BATNAs as your outside options can run into trouble when, as a practical matter for purposes of given interactions, many negotiators are locked in relationships with their counterparts and their no-agreement options are inherently interdependent. (Lax and Sebenius 2006:92) Think of a reasonably content married couple or successful business partners negotiating an issue of keen mutual interest on which they have different preferences. Think of the sole supplier of an essential component negotiating with a customer who is the only source of a highly profitable product that relies on the component. Think of the sales audience for the well-known Harvard Business Review article entitled, "Negotiating with a Customer You Can't Afford to Lose" 
(Keiser 1988). Or in a more adversarial setting, think of a powerful longshoremen's union negotiating with West Coast shippers. "Outside options" for "satisfying your interests without the other's agreement" have limited relevance in many such cases.

During these kinds of negotiations and after the dust settles, the odds are that the two parties will still be together. It may not be very useful to conceptualize your BATNA in such cases as your "tell them to go jump in a lake" possibilities, "your best outside option," or "your best course of action for satisfying your interests without the other's agreement."

Certainly the parties to these negotiations in fact do have genuine outside options that are independent of the other side-divorce, a dissolved partnership, a dropped product line, non-port jobs and the Panama Canal (rather than the ports of San Diego, Los Angeles, and Seattle). But as a practical matter, pure outside "jump in the lake" options that are independent of the other party can be of limited tactical or strategic value in such cases. During and following their negotiations, the parties must continue to interact and will usually remain together. Using one's BATNA to "force" a deal tactically (but with the expectation of continued relations) is very different from using it for genuine strategic "escape" from the relationship. (Walton, Cutcher-Gershenfeld, and McKersie 1994).

In such situations, instead of thinking of your BATNA in terms of "your outside options" that are "independent of the other party," consider a potentially different question: "What are the full consequences of saying my "no" to the other side's proposal (and possibly, continuing to negotiate, with or without a pause)? How can I most accurately play out and perhaps most effectively influence how these consequences will affect each side's interests (preferably positively for you and negatively for them)?" While hardly "outside options independent of the other party," such consequences can include costs or risks borne by each side, foregone benefits, altered settlement possibilities, damage to the relationship, third party effects, and so on.

Suppose, for example, that the passage of time strengthens your financial position in a commercial deal while quickly bankrupting the other side. Then rather than conceptualizing your BATNA in terms of "your outside options independent of the other party," your BATNA might be to keep negotiating with the same counterpart while continuing to say no until your relative situation has sufficiently improved. And even if saying no while still negotiating affects both sides equally or even favors the other side-an empirical matter to be determined by comparing the various possible choices-continuing to negotiate may remain the best alternative to agreement. ${ }^{6}$ Prescriptively, the minimally acceptable agreement for you should have at least the expected value (to you) of the course of actions that would follow a "no."7

Even more serious problem \#3: Treating Your BATNA Mainly as a Last Resort. Conceptualizing one's BATNA mainly as a kind of last resort-as is often 
done-can be unnecessarily limiting. Harvard Business School Professor Francesca Gino (Program on Negotiation 2012:7) frames it thus: Your BATNA is your "fallback alternative, in the event that the parties fail to reach an agreement." Her HBS colleague, Deepak Malhotra, similarly observes (Program on Negotiation 2012:1): "A negotiator's BATNA is the course of action he will pursue if the current negotiation results in an impasse." (Guhan Subramanian, cited above, also linked one's BATNA with "impasse.") Fisher, Ury, and Patton (1991) even introduce the concept of BATNA as the answer to a revealing question, applicable only in specific circumstances of asymmetric power: "What if they are more powerful? (Develop your BATNA...)"-inadvertently implying that if the power scales are tipped in your favor, there is a lesser or no role for a BATNA.

To the contrary, not only as a last resort or just when "they are more powerful," you should evaluate-and possibly enhance-your BATNA as an essential element of preparation, once you have assessed the full set of your interests and envisioned the possibility of a valuable agreement. Martin Lipton, renowned corporate lawyer and specialist in merger and acquisition negotiations, was explicit about the value of enhancing your BATNA by soliciting other parties at the start of negotiations with one counterpart. He even roughly quantified the incremental value of involving an additional competitor early in the process relative to greater negotiating skill in the original two-party deal toward the end: "The ability to bring somebody into a situation is far more important than the extra dollar a share at the back end. At the front end you're probably talking about 50 percent [from adding a competitor, enhancing your BATNA]. At the back end, you're talking about 1 or 2 percent [from greater negotiating skill]." (Subramanian 2003:691) And, of course, you should evaluate the other side's BATNA and consider whether actions to worsen it are warranted.

BATNAs often shift during negotiation as a function of changes in information, the underlying situation, the actions of third parties, or other factors. For example, suppose you learn that you just won a new car while negotiating with a dealer to replace your existing clunker. Say that a judge rules against one side on a key preliminary motion while the disputants are negotiating toward an out-of-court settlement. These dynamic shifts call for continually updating your BATNA assessments, not awaiting impasse to do so (or only doing so if they are more powerful).

Suppose that you are "more powerful" in the sense that you have a terrific BATNA and they have a lousy one. That fact should play a quietly potent role from the very beginning of the process in the hope of your doing even better than your BATNA by an agreement.

Indeed, as very a first resort, you should estimate how well each side's BATNA serve its interests. This is essential to determine the minimum acceptable threshold for any proposed deal. Indeed, the set of agreements that are better for each side than its BATNA, as measured by its interests, defines the zone of possible 
agreement. As a practical matter, while assessing BATNAs is a vital step in preparation for negotiation, exploring interests and inventing creative possible solutions is often more effective when BATNAs are in the background ... rather than being continually brandished.

Of course, BATNAs often play other key roles during negotiations, not just in the case of impasse. Consider a fairly obvious but garden-variety example. Suppose that you adopt a problem-solving approach to a business dispute, but the other side stonewalls and stubbornly insists on an extreme position as the only possible resolution. You probe for underlying interests and suggest mutually preferable options. However, at a certain point during the negotiations, perhaps well before any final impasse is reached, you judge that your cooperative approach is not working. At that point (or before), you may choose to hire high-powered legal counsel, engage consultants to buttress your case, and pre-emptively file suit in a highly favorable jurisdiction-not only about the issue you are negotiating but perhaps on related issues (either for leverage or to with the idea of proposing a "global" settlement of the issues that now affect both parties-both the "original" issues and those issues about which your suit was brought). Or, rather than actually filing suit, you may decide to persuasively warn the other side that this course of action is increasingly likely. Depending on how you successfully you frame your actions to avoid irrational escalation, the other side may now face a credibly worsened BATNA (while yours has been enhanced). With these moves, you may be able to reach a much better deal than was available before your warning or legal actions. Your actions did not need to await impasse. And assessing each side's legal options should have been part of your background preparation even before negotiating.

Notice three aspects of this simple example that relate to the three potential problems with the BATNA concept discussed above.

First, with respect to problem \#1, while this example does not violate the strict characterization of your BATNA as what you could achieve without negotiating, the whole point of such BATNA-related actions is to influence what you can do by negotiating. In fact, negotiating to settle the "BATNA/suit" may heavily influence your "primary/original" negotiation.

Second, with respect to problem \#2, this "outside option" need not be not independent of your counterpart, only of his or her agreement. With a threatened lawsuit in the background, your de facto BATNA may be to keep negotiating with the stubborn party, hoping their stance will soften. Moreover, if separate negotiations to settle the original dispute and to settle the lawsuit are required, you may also negotiate whether to combine the two processes. Thus the two of you would be intimately linked both in negotiation and litigation. Thinking of "outside options, independent of the parties" is not strictly wrong, just potentially misleading in this case and many others like it. 
Third, with respect to problem \#3, the role of one's BATNA in this example need not play a role only at impasse, as a last resort, or mainly when "they are more powerful." This example demonstrates that, while indeed, an irrevocable breakdown of negotiations may trigger a resort to your BATNA, your no-deal options can and often should play important roles before and during negotiations as well. There is typically an ongoing tension between the use of one's BATNA as a tactic (to get a better deal in the current negotiation) and a strategy (a genuine decision to choose an option other than agreement with your current counterpartespecially when doing so implies "escape" by severing any relationship). (Walton, Cutcher-Gershenfeld, and McKersie 1994).

Savvy analysts and practitioners generally avoid these three problems/limitations. Yet many students and more "experts" than one might expect fall prey to potentially serious misunderstandings when they interpret BATNAs to exclude negotiation ("the results you can achieve without negotiating"), when they think only in terms of outside options that are independent of the other party, and when they see their BATNA as relevant only as a last resort, at impasse, or when the other side is more powerful.

Other misconceptions are rife. For example, I often run across versions of the plaintive question "But what if I have no BATNA?" Example: an article by Pollack (2013) is entitled "Negotiating when there is no BATNA." Or, in offering advice on a salary negotiation, the "expert" (Wood 2011) declared "Bill lacked confidence due to his non-existent BATNA." Even in a scholarly treatise, where the authors (Conlon, Pinkley, and Sawyer 2014:331-332) certainly know better (and later make the correct understanding clear), one finds the statement "If Terry has no job currently, one might argue that in terms of a BATNA, Terry has none whatsoever." Moreover, the table explaining their experiments has "No BATNA" as one of six options.

"No BATNA?" If you refuse a deal, some active or passive course of action, desirable or not, is open to you. Nothing in the BATNA concept calls for it to be a good option: no deal with your counterpart may still realistically imply getting fired with no further employment prospects, doing jail time, or giving up your kingdom. Indeed, after a "no," continuing to negotiate may be your best alternative to agreement (along with seeking to develop outside possibilities). The prescriptions remain the same, even if the question about "no BATNA" is phrased illogically: 1) assess your BATNA and theirs, good or poor, and 2) determine if a zone of possible agreement exists (and if so, where it is), as well as 3 ) consider enhancing your BATNA, and, possibly, worsening theirs.

One reason, David Lax and I chose to largely avoid the BATNA acronym in our 2006 book, 3-D Negotiation - in favor of the phrase "no-deal option"-was to avoid these distressingly common misconceptions and misuses of this valuable concept. We typically ask "what happens in the event of no deal during negotiation as well as at a possible impasse: do you walk away, continue negotiating, build up your no-deal option, and/or worsen theirs? If you say "no", what set of possibilities 
is likely to unfold? How good or bad is this course of action for you and the other side(s)?" But we seek to avoid the mistaken implications highlighted above: that your no-deal option does not involve negotiation, that it should mainly be thought of as an outside option independent of the other side, and that it is primarily a last resort or only relevant if you feel weak.

Given the value and runaway success of the phrase, BATNA, we do not seek to banish it from the realm of negotiation analysis and practice. It is just too useful and memorable. At a minimum, however, we should be clear that when you say "my BATNA is ...," it is not a global statement. Instead, you should implicitly mean your best alternative "with respect to" a specific counterpart, a particular proposed agreement or class of agreements, and/or a definite time period or stage in the negotiation process.

Indeed, we'd like to see this important concept routinely characterized and explained more accurately. In tandem with the term BATNA, it might help to explicitly refer to "three nos" as distinct reasons to refuse a proposed negotiated agreement.

First is a "tactical no," simply turning down a proffered deal in hopes of generating a better offer later in the process.

Second, is a "no to re-set." Like the lawsuit example above, this "no" may occur at any stage of the process. It can entail moves "away from the table" to improve your own no-deal option and/or worsen that of the other side. You often employ the "no to re-set" with the intention of continuing to bargain or returning to active negotiation with your original counterpart, but in a setup that that you have more actively modified to be more conducive to reaching your preferred deal. ${ }^{8}$

Third, you may utter and mean a "final no," or the course of action you'd take if a sufficiently desirable agreement simply does not seem feasible with your counterpart.

If and when you utter a "tactical no," a "no to re-set," or a "final no," you should assess the implications by analyzing the same questions: how you envision and evaluate the process playing out from the point of actually conveying your "no"? What does this mean for your minimum conditions going forward? Theirs? The prospects for a more favorable deal? And so on.

In short, a great virtue of a focus on one's BATNA is the discipline of systematically asking of any possible deal: "as compared to what?" The acronym has proved irresistible but common descriptions can be problematic or worse. It would enhance clarity to emphasize that, typically, one's BATNA is only meaningful with respect to a specific counterpart and class of possible deals with that counterpart. And some tweaks that distinguish among the three types of "no" could enhance the value of "BATNA" even further. 
1 Professor, Harvard Business School (jsebenius@hbs.edu). I thank David Lax for many clarifying conversations on this subject. Greg Barron, Max Bazerman, Emily Bolon, Joel Cutcher-Gershenfeld, Paul Levy, Nancy Waters, and Michael Wheeler have offered useful suggestions.

2 See Fisher, Ury and Patton (1991) and, e.g., Raiffa (1982), and Lax and Sebenius (1986).

${ }^{3}$ Often true, but the concept of bargaining "power" is notoriously tricky. And improving one's alternatives to negotiated agreement need not imply an improved bargaining position. For example, in negotiating with one's spouse, letting it be known that you have cultivated an excellent alternative to him or her-just in case the current deal doesn't go your way-may well backfire. Similarly, burning your bridges may worsen your no-deal option, but enhance your bargaining power by credibly enhancing your willingness to fight. For a much more nuanced discussion of "power" in negotiation, see, especially, Chapters Six and Ten in Lax, D.A. and J.K. Sebenius (1986).

${ }^{4}$ See Fisher, Ury and Patton (1991) and, e.g., Raiffa (1982), and Lax and Sebenius (1986).

${ }^{5}$ For guides to this extensive literature, see Lax and Sebenius $(1985,1986)$; Lax (1985), Raiffa (1982); Raiffa, H., J. Richardson and D. Metcalfe (2002); and Lax and Sebenius (2006).

${ }^{6}$ Lax and Sebenius (1985: 165) made this point explicitly.

${ }^{7}$ Analytic techniques for making this assessment are beyond the scope of this short article, but can be found in Raiffa (1982) and Lax and Sebenius (1985).

${ }^{8}$ In 3-D Negotiation, David Lax and I (20016) systematically analyze several elements of a negotiation-the parties, issues, interests, no-deal options/BATNAs, as well as the sequence and basic process orchestration - not as givens, but as choice variables that may be favorably modified by conscious tactical choice. Such actions to change a negotiation's setup can produce a more promising situation for reaching a target agreement.

\section{References}

Conlon, D., R.L. Pinkley, and J.E. Sawyer 2014."Getting something out of nothing: reaping or resisting the power of a phantom BATNA." Pp328-342, Chapter 20, in Ayoko, O.B., N. M. Ashkanasy, and K. A. Jehn, eds. Handbook of Conflict Management Research. Cheltenham, UK: Edward Elgar.

Fisher, R., W. Ury and B. Patton. 1991. Getting to Yes. New York, Penguin.

Keiser, T.C. 1988. Negotiating with a Customer You Can't Afford to Lose. Harvard Business Review. Nov/Dec 66(6): 30-34.

Lax, D. A. 1985."Optimal Search In Negotiation Analysis." Journal of Conflict Resolution vol. 29, no. 3 : 456-472.

Lax, D. A. and J. K. Sebenius 1985. "The Power of Alternatives or the Limits to Negotiation." Negotiation Journal 1(2): 163-179. 1986. The Manager as Negotiator. New York: Free Press. 2006. 3-D Negotiation. Boston: Harvard Business Press.

Pollack, P.G. 2013. "Negotiating when there is no BATNA" Mediate.com at http://www.mediate.com/articles/PollackPbl20130908.cfm

Program on Negotiation 2012. "BATNA Basics: Boost Your Power at the Bargaining Table." Harvard Law School. Cambridge: MA.

Raiffa, H. 1982. The Art and Science of Negotiation, Cambridge: The Belknap Press of Harvard University Press.

Raiffa, H., J. Richardson and D. Metcalfe 2002. Negotiation Analysis: The Science and Art of Collaborative Decision Making. Cambridge, Belknap Press of Harvard University Press.

Rivlin, G. 2000. "AOL's Rough Riders," The Standard, http:///www.thestandard.com/article/displa/0.1151.19461.00.htm.

Rubin, R.E. and J. Weisberg 2003. In an Uncertain World: Tough Choices from Wall Street to Washington. New York: Random House. 
Sebenius, J.K. and R. Fortgang (1999). "Steve Perlman at Web TV(B)" Case 9-899-271 Boston: Harvard Business School.

Spangler, B. 2012."Best Alternative to Negotiated Agreement," in Beyond Intractability, http://www.beyondintractability.org/essay/batna.

Subramanian, G. 2003. "The Drivers of Market Efficiency in Revlon Transactions." Journal of Corporate Law vol. 28, No. 4. pp. 691-714.

Ury, W. 1991. Getting Past No. New York Bantam.

Watkins, M. (1999). "Strategic Dealmaking at Millennium Pharmaceuticals." Case 899-242. Boston: Harvard Business School.

Walton, R. E., J. Cutcher-Gershenfeld, and R. B. McKersie 1994. Strategic Negotiations: A Theory of Change in Labor-Management Relations. Boston, Harvard Business School Press.

Wood, T. 2011. "Negotiating Salary: Tactics, Blunders, or Best Negotiating Practices - Part III." at https://www.watershedassociates.com/negotiationblog/negotiating-salary-tacticsblunders-or-best-negotiating-practices-part-iii\#sthash.Fb20Vg3N.dpuf. 